\title{
High Voltage Ride through Control of PMSG-Based Wind Turbine Generation System Using Supercapacitor
}

\author{
Guangchen Liu $\mathbb{D}^{1,2}$ Jianwen Hu, ${ }^{1}$ Guizhen Tian, ${ }^{1}$ Lie Xu, ${ }^{3}$ and Shengtie Wang ${ }^{4}$ \\ ${ }^{1}$ Inner Mongolia University of Technology, Hohhot 010051, China \\ ${ }^{2}$ Inner Mongolia Regional Key Laboratory of Electrical Power Conversion, Transmission and Control, Hohhot 010051, China \\ ${ }^{3}$ University of Strathclyde, Glasgow G1 1XW, UK \\ ${ }^{4}$ Inner Mongolia Electronic Information Vocational Technical College, Hohhot 010070, China
}

Correspondence should be addressed to Guangchen Liu; liugc@imut.edu.cn

Received 21 September 2018; Revised 14 March 2019; Accepted 2 April 2019; Published 2 May 2019

Academic Editor: Luigi Di Benedetto

Copyright (c) 2019 Guangchen Liu et al. This is an open access article distributed under the Creative Commons Attribution License, which permits unrestricted use, distribution, and reproduction in any medium, provided the original work is properly cited.

Regarding PMSG-based wind turbine generation system, this paper proposes a supercapacitor energy storage unit (SCESU) which is connected in parallel with the DC-link of the back-to-back converter to enhance its high voltage ride through performance. The analysis of the operation and control for the grid-side converter and SCESU are conducted. Based on real time digital simulators (RTDS), a model and a Hardware-in-the-Loop (HiL) platform of PMSG-based wind turbine with SCESU is developed, and the simulation results show that the SCESU absorbs the imbalanced energy and the grid-side converter absorbs inductive reactive power during the period of voltage swell and verify the correctness and feasibility of the high voltage ride through control strategy.

\section{Introduction}

In the past, wind turbine generation system (WTGS) was allowed to disconnect from the grid during grid voltage sag or swell. However, with the high penetration of wind power in power systems in many countries, grid codes become stricter and require the fault ride-through capacity of WTGS, including high voltage ride through (HVRT) and low voltage ride-through (LVRT) profiles during which WTGS must remain connected and supply the expected reactive power to support the utility grid [1]. The latter has already received significant attention and explored in many literatures [2-7], and the former is an emerging issue and being paid more and more attention now.

The requirement for HVRT capability of WTGS will be more stringent in many grid codes when the penetration level of wind power in power system is increasing higher and higher. For example, the Australian new national electricity rules require that WTGS must maintain continuous uninterrupted operation for temporary overvoltage for the magnitudes and durations specified as 1.1 1.15pu for 1200s, 1.15 $1.2 \mathrm{pu}$ for $20 \mathrm{~s}, 1.2 \sim 1.25 \mathrm{pu}$ for $2 \mathrm{~s}, 1.25 \sim 1.3 \mathrm{pu}$ for $0.2 \mathrm{~s}$, and
1.3 1.4pu for $0.02 \mathrm{~s}$. Additional inductive reactive current of $6 \%$ of the normal current for each $1 \%$ increase at point of common coupling (PCC) voltage above 1.1pu is also required [8].

The operation time of WTGS (see Table 1) is only specified in technical regulation for wind farm reactive power configuration and voltage control of State Grid Corporation of China, but the ratio of reactive current and grid voltage is not provided during voltage swell [9].

Existing technologies for implementing HVRT of WTGS can be divided into two categories: using improved control scheme and the use of additional auxiliary device. In [10], HVRT of grid-side converter (GRSC) is realized by increasing the DC-link voltage and reactive current based on an adaptive adjustment algorithm, but the DC voltage and/or the current of GRSC will exceed the rated values during HVRT. In [11], a hybrid current control scheme is implemented in both the rotor and the grid-side converters of doubly-fed induction generator (DFIG) based WTGS to enhance its high voltage ride-through capacity, but supplied reactive power to the grid is not discussed. 
TABLE 1: HVRT requirement of State Grid Corporation of China.

\begin{tabular}{lc}
\hline Grid voltage $(\mathrm{pu})$ & Operation time \\
\hline $1.10 \sim 1.15$ & $2 \mathrm{~s}$ every time \\
$1.15 \sim 1.20$ & $0.2 \mathrm{~s}$ every time \\
$>1.20$ & Take off \\
\hline
\end{tabular}

In [12], the self-adaptive control strategy of DC-link voltage and the carrier-based overmodulation strategy for a 3-level GRSC are adopted during HVRT, and a DC chopper is used to consume the excess energy during HVRT. In $[13,14]$, in addition to the use of a DC braking resistor GRSC is controlled to provide inductive reactive power to the grid. The generated power in [12-14] is reduced because the imbalanced energy is consumed by the DC breaking resistance rather than fed into the grid. In [15], a STATCOM connected to the PCC bus is applied to absorb reactive power from the grid to enhance the HVRT of the WTGS. However, this method is only applicable for weak grid in which the voltage at the PCC can be reduced by the STATCOM's reactive power absorption. In [16], a superconducting magnetic energy storage (SMES) unit connected in parallel with the PCC bus is proposed to improve HVRT performance of DFIG-based WTGS. In [17], a rotor crowbar circuit and a DC chopper are used to protect the rotor side converter against overcurrent and limit the DC voltage during HVRT, respectively. In [18], a dynamic voltage restorer placed in series between the PCC bus and the grid and a static shunt compensator connected at the PCC bus are investigated to ensure DFIG-based WTGS to comply to the new HVRT grid code requirements.

In this paper, the supercapacitor energy storage unit (SCESU) is selected to improve the HVRT capability of the PMSG-based WTGS, and the coordinated control strategy is presented. It will be shown that SCESU can add the missing HVRT capability to the WTGS in order to become compliant to grid code, even if it is getting stricter. Furthermore, SCESU does not reduce generated power of WTGS and its control strategy is simple.

This paper is organized as follows. Section 2 presents the principle of PMSG-based WTGS with SCESU and discusses the regulation mechanism of GRSC under voltage swell. Section 3 introduces the improved control strategy for GRSC and SCESU. In Sections 4 and 5, simulations are performed based on RTDS and Hardware-in-the-Loop (HiL) platform to assess the HVRT control validity respectively whereas in Section 6 conclusions are summarized.

\section{Analysis of HVRT Scheme}

2.1. GRSC Operation. The block structure of a grid-tied PMSG-based WTGS with SCESU which is connected in parallel with the DC-link capacitor of the back-to-back converter is shown in Figure 1. The generator-side converter (GESC) and GRSC are independently controlled because of the decoupling effect of the DC-link capacitor. Respectively, the field- and voltage-oriented control (FOC and VOC) generate

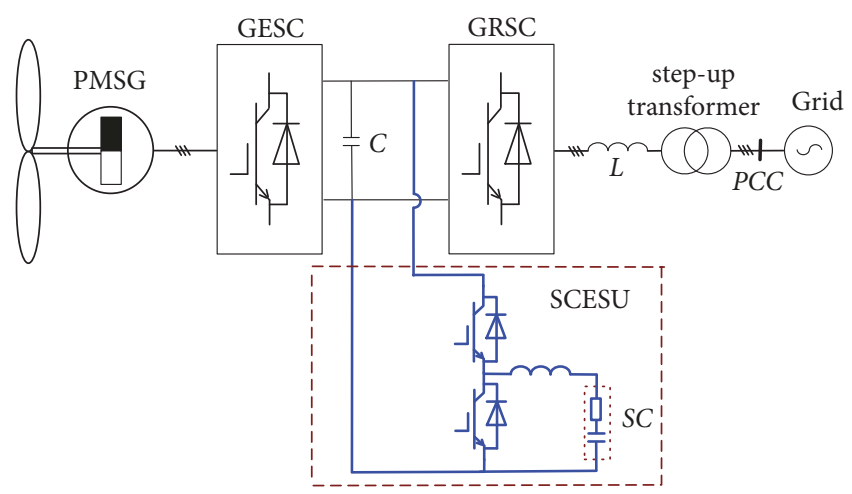

FIGURE 1: Structure diagram of PMSG-based WTGS with SCESU.

switching signals for GESC to achieve maximum power point tracking and GRSC to achieve unit power factor control of AC input and maintain voltage stability in DC-link under normal grid conditions. When grid voltage swell occurs, the most critical condition is when the PMSG generates the rated power. Therefore, it is assumed that FOC is used in the GESC and the active power injected into the DC-link from the GRSC is at rated value in this paper.

When VOC is employed to control the GRSC, the GRSC voltage, current, and output power can be represented as [2]

$$
\begin{aligned}
& u_{g d}=-\left(L \frac{\mathrm{d} i_{d}}{\mathrm{~d} t}+R i_{d}\right)+\omega L i_{g q}+e_{g d} \\
& u_{g q}=-\left(L \frac{\mathrm{d} i_{q}}{\mathrm{~d} t}+R i_{q}\right)-\omega L i_{g d}+e_{g q} \\
& i_{g}=\sqrt{i_{g d}^{2}+i_{g q}^{2}} \\
& P_{g}=\frac{3}{2}\left(e_{g d} i_{g d}+e_{g q} i_{g q}\right)=\frac{3}{2} e_{g d} i_{g d} \\
& Q_{g}=-\frac{3}{2}\left(e_{g d} i_{g q}-e_{g q} i_{g d}\right)=-\frac{3}{2} e_{g d} i_{g q}
\end{aligned}
$$

where $u_{g d}$ and $u_{g q}$ are the d- and q-axis voltages of the GRSC output, respectively. $e_{q d}, e_{g q}, i_{g d}$, and $i_{g q}$ are the d-and q-axis grid voltages and currents, respectively. $i_{g}$ is the peak phase current, and $L$ and $R$ are the respective filter inductance and resistance.

In order to analyse the influence of the voltage swell on the GRSC, the small-signal modelling of the GRSC active power is given as

$$
P_{g}=\frac{3}{2}\left(e_{g d}+\Delta e_{g d}\right)\left(i_{g d}+\Delta i_{g d}\right)
$$

where the small-signal variables $\Delta e_{d}$ and $\Delta i_{d}$ are the partial differential components of the grid voltage and current, respectively.

Considering $P_{g}$ is constant yields

$$
\Delta i_{g d}=-\frac{i_{g d}}{e_{g d}} \Delta e_{g d}
$$


Equation (3) shows that when the grid voltage rises, $\Delta e_{g d}>$ 0 , and then $\Delta i_{g d}<0$. It means that $i_{g d}$ will reduce during voltage swell; i.e., $i_{g p c c}$ will reduce because VOC is used in GRSC control.

By ignoring $R$ the modulation index of SPWM used in GRSC is

$$
m \approx \frac{2 U_{B} L}{u_{d c}} \sqrt{i_{g}^{2}+2 i_{g q} \frac{e_{g d}}{L}+\left(\frac{e_{g d}}{L}\right)^{2}}
$$

where the base value of voltage $U_{B}$ is the peak phase voltage and $u_{d c}$ is the DC-link voltage.

When the unit power factor control based on VOC is used in the GRSC, $i_{g q}$ is zero, there is

$$
m \approx \frac{2 U_{B} L}{u_{d c}} \sqrt{i_{g}^{2}+\left(\frac{e_{g d}}{L}\right)^{2}}
$$

As can be seen from (5), $m$ will increase because the grid voltage $e_{g d}$ increases. The harmonic current content in GRSC increases with the increase of $m$, and then the loss and temperature of GRSC will also increase, which can damage GRSC. Furthermore; when $m$ increases and even reaches its upper limit, GRSC will reduce its control margins and even be out of control. This also could destroy the WTGS because of continuous overvoltage of the DC-link capacitors or GRSC overcurrent during the whole process of the high voltage condition.

It can be found from (4) that there are two ways to avoid increasing $m$; one is to increase $u_{d c}$, and the other is to increase the lagging current $i_{g q}$ to absorb inductive reactive power from the grid. The latter is adopted in this paper though the active power injected to the grid has to be reduced because of GRSC's limited current capability. SCESU is adopted to store the excess energy between GESC and GRSC during voltage swell, which is then discharged when the grid returns to normal operation.

2.2. SCESU Design. The SCESU consists of a super capacitor (SC) and a bidirectional DC/DC converter, as shown in Figure 1. SC charges and stores electric energy during HVRT, which is controlled by the DC/DC converter operating as a Buck converter. When the fault is cleared and the output power of PMSG is below a certain value (e.g., $0.8 \mathrm{pu}$ ), SC discharges to its initial state and is ready for next HVRT. In this case, power flows from SC to DC-link and the DC/DC converter operates as a Boost converter. The operating voltage range of SC is set to $0.3 \sim 1.0 \mathrm{kV}$ on the basis of the controllable duty range and the DC-link voltage. swells.

The SC capacity is calculated based on two typical voltage

2.2.1. Voltage Swell to $1.2 p u$ for $200 \mathrm{~ms}$. In this case, the reactive current reference is $-0.78 \mathrm{pu}$ (calculated by (12) in Section 3.2, and all calculations in this paper are based on a per unit system), and the current limit of GRSC is $1 \mathrm{pu}$; therefore the active current of GRSC is

$$
i_{\text {gd }}=\sqrt{i_{\text {gmax }}^{2}-i_{\text {gqref }}^{2}}=0.63 \mathrm{pu}
$$

The maximum active power of SC during HVRT, i.e., the difference between the active power of GESC and DRSC, is given by considering 1 pu active power from PMSG as

$$
P_{s c}=P_{g}-e_{g d} i_{g d}=0.244 \mathrm{pu}
$$

During this period, the energy stored by SC is

$$
W_{s c}=P_{s c} \Delta t=0.244 \times 1.5 \times 10^{6} \times 0.2=7.32 \times 10^{4} \mathrm{~J}
$$

The maximum amount of energy that can be stored in SC during the period is determined by its maximum and the minimum voltages as

$$
W_{s c}=\frac{1}{2} C_{s c}\left(u_{s c \max }^{2}-u_{s c \min }^{2}\right)
$$

Thus, the required capacitance of SC is derived by solving (8) and (9) as

$$
C_{s c}=0.16 F
$$

2.2.2. Voltage Swell to 1.15pu for 2s. Based on the same calculation process, the capacitance of SC is given in this case as

$$
C_{s c}=0.30 F
$$

According to the above calculation (10) and (11), the capacitance of SC is set $0.3 \mathrm{~F}$.

Because the bidirectional DC/DC converter is a conventional Buck-Boost converter, no further discussion on its design is given here.

\section{HVRT Control of PMSG-Based WTGS}

3.1. HVRT Control Scheme. In order to realize HVRT control, a set of control logics of PMSG-based WTGS with SCESU are developed based on the finite state machine design method, as shown in Figure 2. When "Fault Control" is activated and the flag of overcurrent is received, the GESC, GRSC, and SCESU are "Switch off", and all PI regulators are reset with their references setting as same as the feedback values to avoid saturation, as shown in State 1. When "HVRT Control" is activated due to the flag of voltage swell, reactive current priority control (RCPC) of GRSC is executed to absorb inductive reactive power and SCESU charges to store the imbalance energy between GESC and GRSC, as shown in State 2. When the PCC voltage recovers, State 2 switches to State 3. In State 3, once the PMSG output is under a certain value, SCESU discharges to supply electric energy back to the grid. The WTGS returns to "Normal Control" (State 0) when SCESU discharges to SC minimum voltage. 


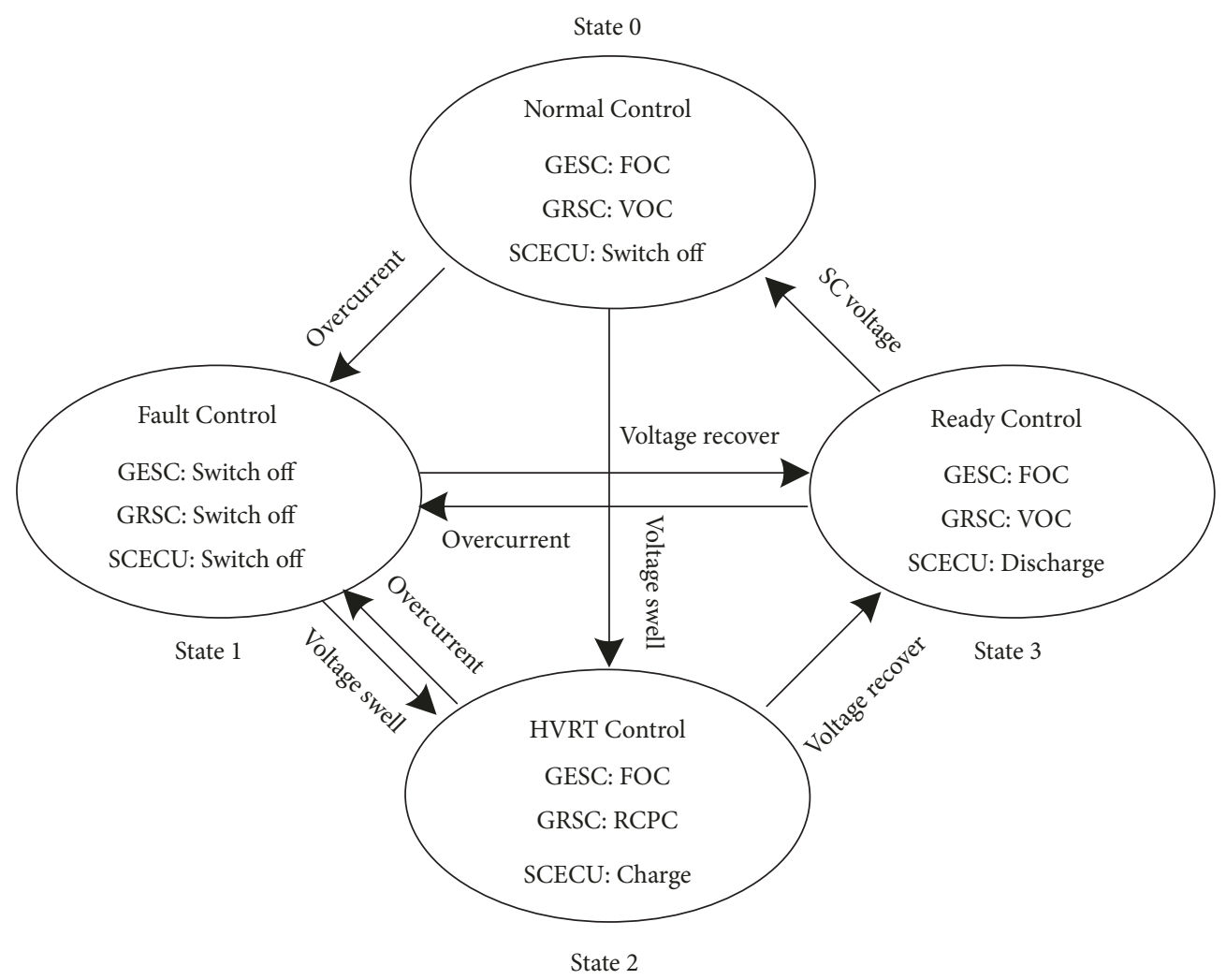

FiguRE 2: HVRT control scheme.

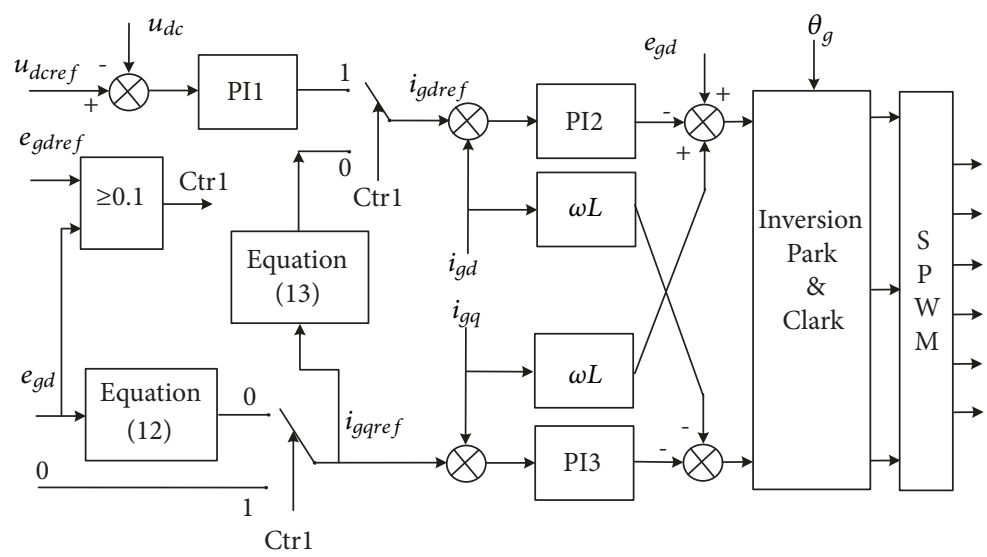

FIgURE 3: Control scheme of GRSC.

3.2. Control of GRSC. The detailed block diagram of the proposed control of GRSC is shown in Figure 3. Ctr1 represents the control mode by measuring the grid voltage. Its value is set to " 1 " during normal grid condition with the conventional VOC being adopted while it is " 0 " during grid voltage swell with the reactive current precedence control being adopted.

The specific requirements for reactive power generation as function of AC voltage were not considered in [9] during voltage swell. Considering the depth of grid voltage swell and the limit of the GRSC modulation, the reactive current reference is calculated as

$$
i_{\text {gqref }} \approx \frac{\left(a^{2}-k_{i}^{2}\right) i_{g}^{2} L+\left(a^{2}-k_{v}^{2}\right) / L}{2 k_{v}}
$$

where $a$ is the allowable increase ratio of $m ; k_{i}$ is the ratio of the limit and the rated current of GRSC; and $k_{v}$ is the ratio of the swell and rated voltage. 


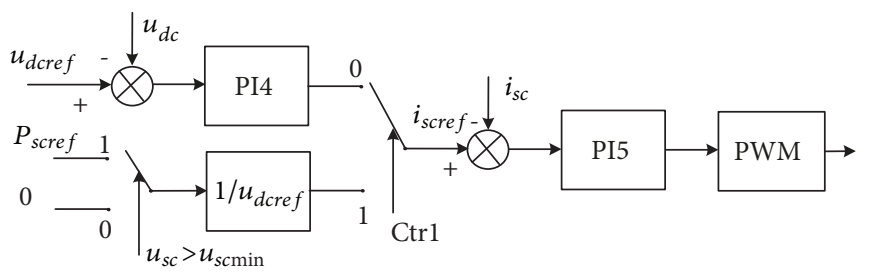

FIGURE 4: Control block diagram of SCESU.

The active current reference is set to protect GRSC current to be less than its maximum allowable value $i_{\text {gmax }}$ as

$$
i_{\text {gdref }}=-\min \left(\sqrt{i_{\text {gmax }}^{2}-i_{\text {gqref }}^{2}}, \frac{u_{d c} i_{d c}}{e_{g d}}\right)
$$

3.3. Control of SCESU. Figure 4 shows the control block diagram of SCESU. Ctrl is set to " 0 " during grid voltage swell, and DC voltage outer loop and current inner loop are used to control SCESU to absorb the imbalance energy and maintain voltage stability in the DC-link. Ctrl is " 1 " during normal grid condition and the active power output of WTGS is less than its rated power, and SCESU is discharged until the supercapacitor voltage reaches its lower limit.

\section{Simulation and Analysis}

The preliminary simulation results obtained in RTDS/ RSCAD are presented in [19] to compare the HVRT performance of the PMSG-based WTGS without and with SCESU installed. Two comparative test scenarios are considered: voltage swell to $1.2 \mathrm{pu}$ for $200 \mathrm{~ms}$ and voltage swell to $1.15 \mathrm{pu}$ for $2 \mathrm{~s}$. Compared with the system without SCESU, the HVRT performance of the system is enhanced significantly in the system with the SCESU installed. The proposed scheme can maintain the DC-link voltage at constant and the harmonic content of the GRSC current is reduced remarkably. The transient oscillations are also alleviated at the same time. The results demonstrate the feasibility and effectiveness of the installed SCESU in enhancing HVRT performance of the PMSG-based WTGS. In this paper, more detailed simulation and hardware-in-loop (HiL) test results are presented.

A detailed simulation model is built in the RTDS/RSCAD software to assess the HVRT performance of a 1.5MW PMSGbased WTGS with SCESU when the grid voltage swells. In the simulated system, the DC-link voltage is $1.22 \mathrm{kV}$; the capacity and voltages ratings of the step-up transformer are 1.6MVA and $0.69 / 35 \mathrm{kV}$; and the pretrigger time in simulation is $20 \%$. In the simulation tests, is it assumed that the PMSG is running at the rated operation state. The simulation tests are carried out for the two following scenarios.

4.1. Voltage Swell to $1.2 p u$ for $200 \mathrm{~ms}$. In this test, the three-phase symmetrical voltage swells to $1.2 \mathrm{pu}$ at $0.8 \mathrm{~s}$ and recovers to $1.0 \mathrm{pu}$ at $1.0 \mathrm{~s}$, lasting for 200 milliseconds. The

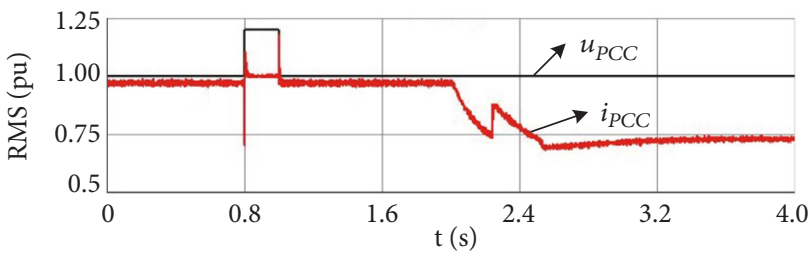

(a) Voltage and current of PCC

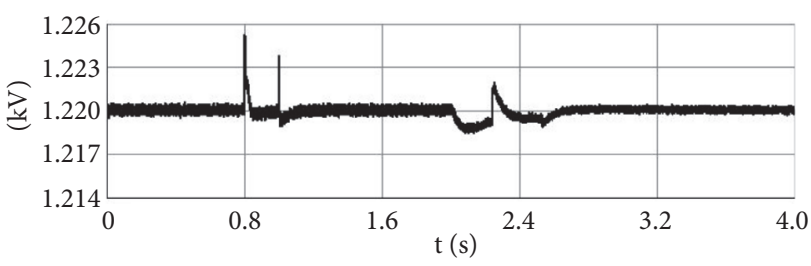

(b) DC-link voltage $u_{d c}$

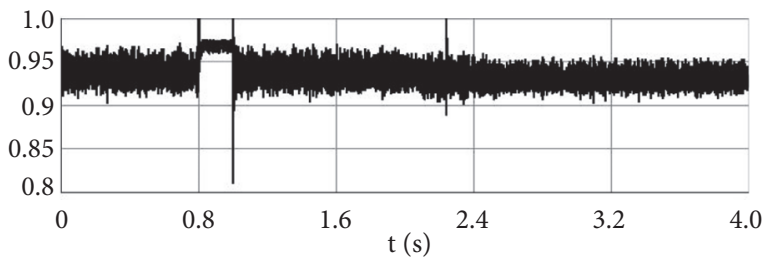

(c) Modulation of GRSC $m$

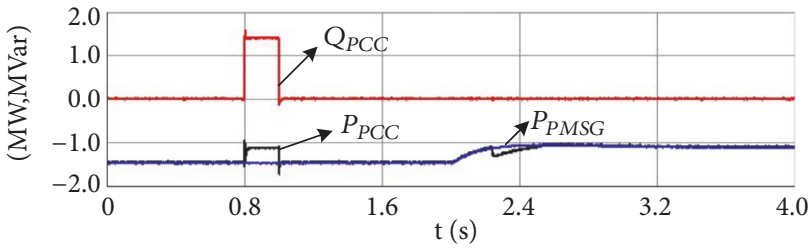

(d) Active and reactive power

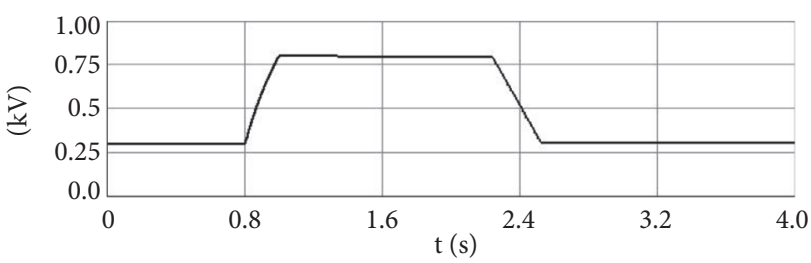

(e) Supercapacitor voltage $u_{s c}$

FIGURE 5: Response of GRSC with SCESU under voltage swell to $1.2 \mathrm{pu}$.

corresponding test results are shown in Figure 5. As seen in Figure 5, when the grid voltage swells, the DC-link voltage $u_{d c}$ is practically maintained constant except the transient 
fluctuations, and the modulation index $m$ fluctuates between 0.9 and 0.95 approximately. The GRSC and PCC current (flowing to the grid) are also regulated within the acceptable ranges. When the grid voltage increases the active power $P_{P C C}$ reactive power $Q_{P C C}$ at $P C C$ increase as well. The SC voltage is increased from $0.3 \mathrm{kV}$ to $0.8 \mathrm{kV}$ because the excess energy caused by the voltage swell is charged into SC.

The grid voltage recovers at $1.0 \mathrm{~s}$ and the system can operate in the steady state established previously. At $2.2 \mathrm{~s}$, the PMSG output is reduced to $0.75 \mathrm{pu}$. In order to compensate for this reduction, the SC is regulated to discharge to release the stored energy and deliver it to the grid until the SC voltage is reduced to $0.3 \mathrm{kV}$. It can be concluded from these results that the proposed scheme with SCESU can provide the system with the enhanced HVRT capability during voltage swell from $0.8 \mathrm{~s}$ to $1.0 \mathrm{~s}$. The excess energy is utilized to compensate for the PMSG output reduction. The HVRT performance in this test meets the second requirement in Table 1.

4.2. Voltage Swell to 1.15pu for $2 \mathrm{~s}$. In this test, the grid voltage rises to $1.15 \mathrm{pu}$ at $1.0 \mathrm{~s}$ and returns to $1.0 \mathrm{pu}$ at $3.0 \mathrm{~s}$, lasting for two seconds. The test results are depicted in Figure 6. As seen in Figure 6, the DC-link voltage is regulated at constant except some transient parts. GRSC absorbs 0.98MVar inductive reactive power from $1 \mathrm{~s}$ to $3 \mathrm{~s}$ and reduces its active power output to $1.4 \mathrm{MW}$ due to current limit. SCESU stores the excess active power and, consequently, the voltage of the supercapacitor increases from $0.3 \mathrm{kV}$ to $0.865 \mathrm{kV}$. Similar to the previous scenario, after the grid voltage recovers and the PMSG output reduction is detected, the SCESU discharges and delivers the stored energy to the grid and SC voltage decreases to $0.3 \mathrm{kV}$. The HVRT performance in this test meets the first requirement in Table 1.

\section{Hardware-in-the-Loop Simulation Design and Analysis}

5.1. Design of HiL Test Platform. In order to further verify the feasibility of the proposed HVRT control, a control Hardware-in-the-Loop (HiL) test platform is investigated to reduce the high development cost and technical difficulties. In the HiL test platform, the PMSG-based WTGS and the power circuit of SCESU are modelled in RTDS, and the controller is implemented is a real-time digital signal processor (DSP). The interface between RTDS and DSP is shown in Figure 7. The gigabit transceiver analogue output card (GTAO) is used to send signals (such as the voltages $u_{P C C}, u_{d c}$ and $u_{S C}$, the current $i_{S C}$, and the output power of PMSG $P_{P M S G}$ ) from RTDS to the external DSP, and the gigabit transceiver digital input card (GTDI) is used to interface PWM signals for the SCESU's semiconductor switches from the DSP to the RTDS. The photo of the HiL platform is shown in Figure 8.

5.2. Test Results and Analysis. The results of the HiL tests for the PMSG-based WTGS with SCESU are shown in Figures

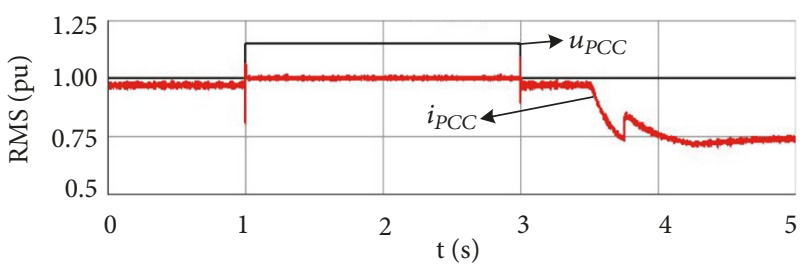

(a) Voltage and current of PCC

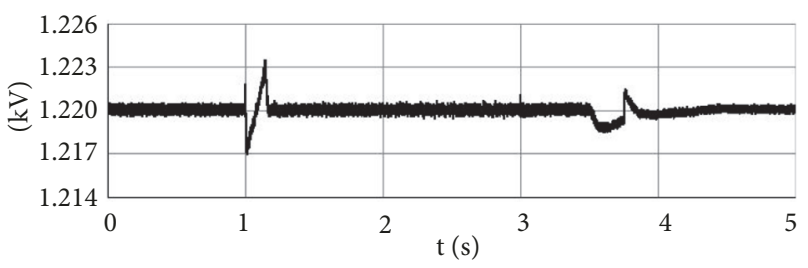

(b) DC-link voltage $u_{d c}$

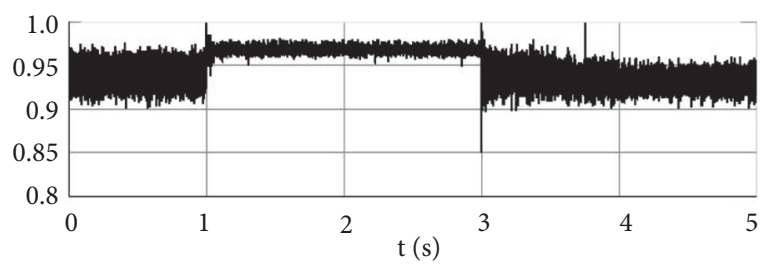

(c) Modulation of GRSC $m$

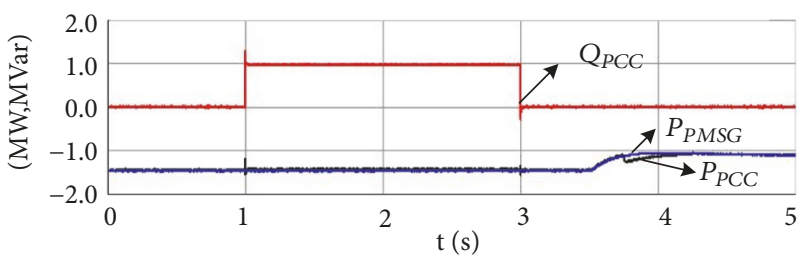

(d) Active and reactive power

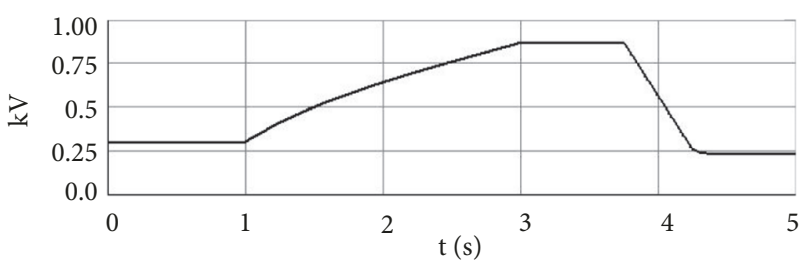

(e) Supercapacitor voltage $u_{s c}$

FIGURE 6: Response of GRSC with SCESU under voltage swell to 1.15 pu.

9 and 10 corresponding to the simulation tests in Figures 5 and 6 , respectively. As seen in these results, it is concluded that the HiL test results closely match the simulation results presented previously. The slight differences between the results of RTDS simulation and HiL test are caused by the delay of GTAO card (about 6 8 micro seconds) and GTDI card (about 1 2 micro seconds). These results illustrate the enhanced HVRT performance with the proposed scheme and the performance complies with the requirements in Table 1. The correctness and feasibility of the proposed HVRT control scheme based on SCESU are further verified in the HiL test platform. 


\begin{tabular}{|c|c|c|c|c|}
\hline \multicolumn{2}{|l|}{ RTDS } & & \multicolumn{2}{|r|}{ DSP } \\
\hline \multirow{7}{*}{$\begin{array}{l}\text { The simulation } \\
\text { model of the } \\
\text { PMSG-based } \\
\text { WTGS with } \\
\text { SCESU power } \\
\text { circuit }\end{array}$} & Channel 1 & ${ }^{u_{P C C}}$ & ADCINA0 & ADC \\
\hline & Channel 2 & $u_{S C}$ & ADCINA1 & \\
\hline & Channel 3 & $i_{S C}$ & ADCINA2 & \\
\hline & Channel 4 & $P_{\text {DMc }}$ & ADCINA3 & code of the \\
\hline & Channel 5 & $P$ PMSG & ADCINA4 & controller for \\
\hline & & DWW & & \\
\hline & Channel \#1 & PWM & EPWM1A & \\
\hline GTDI & Channel \#2 & PWM & EPWM2A & PWM \\
\hline
\end{tabular}

FIGURE 7: Connection diagram of RTDS and DSP.

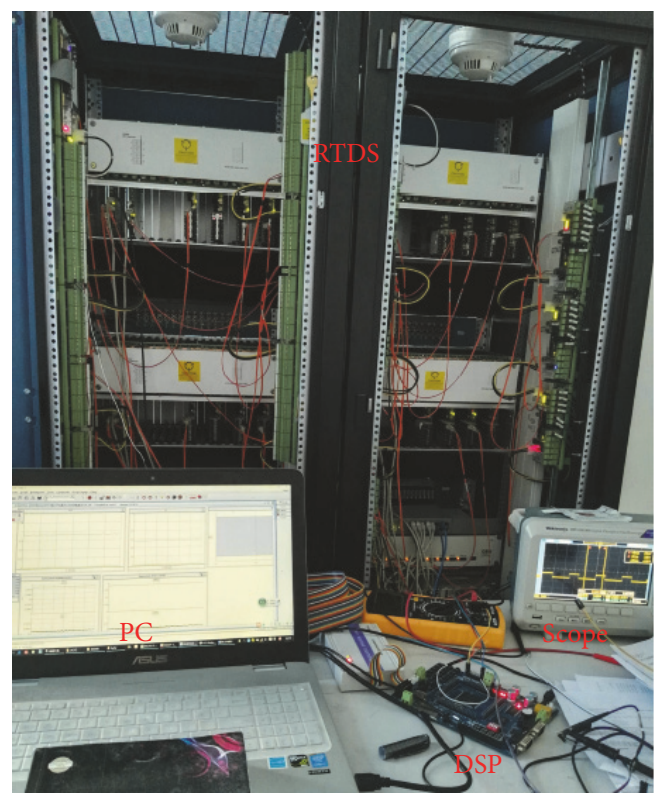

Figure 8: Photo of the HiL platform.

\section{Conclusions}

This paper comes up with a potential HVRT solution for the PMSG-based WTGS based on the theoretical analysis of GRSC operation. In the proposed scheme, the SCESU is connected in parallel with the DC link of the backto-back converter. SCESU stores the imbalanced energy between GESC and GRSC when the voltage swell occurs and releases the stored energy to the grid when the PMSG output decreases. The PMSG-based WTGS can remain operational and absorb inductive reactive power from the grid during voltage swell and the PMSG output reduction can be compensated using the energy stored in SC. The HVRT capability of the PMSG-based WTGS is enhanced by the proposed scheme and corresponding controllers. The HVRT performance meets the relevant requirement. The results obtained in the RTDS simulation and HiL tests verify the feasibility and effectiveness of the proposed HVRT solution.

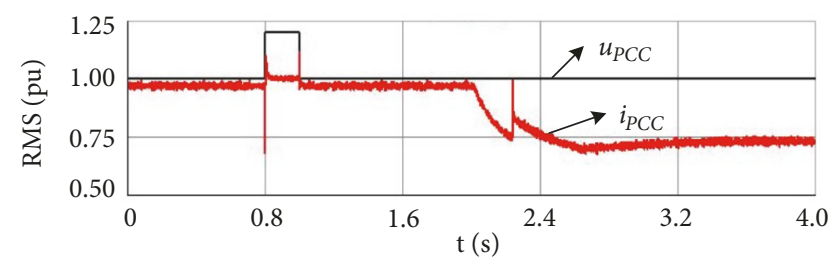

(a) Voltage and current of PCC

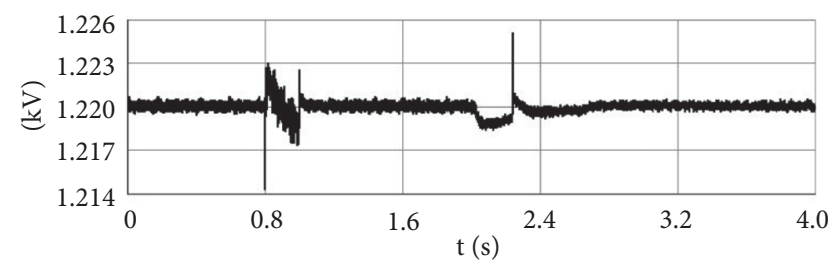

(b) DC-link voltage $u_{d c}$

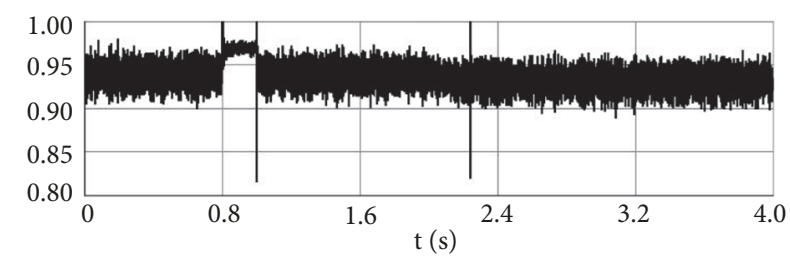

(c) Modulation of GRSC $m$

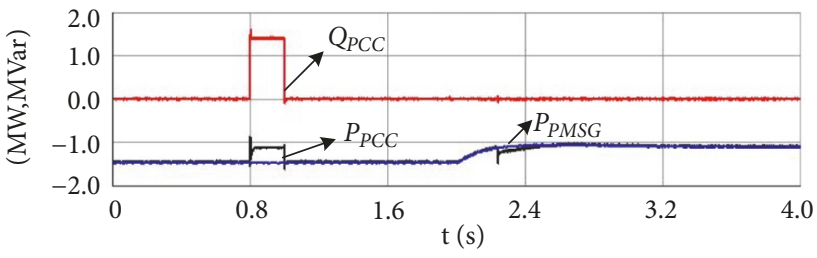

(d) Active and reactive power

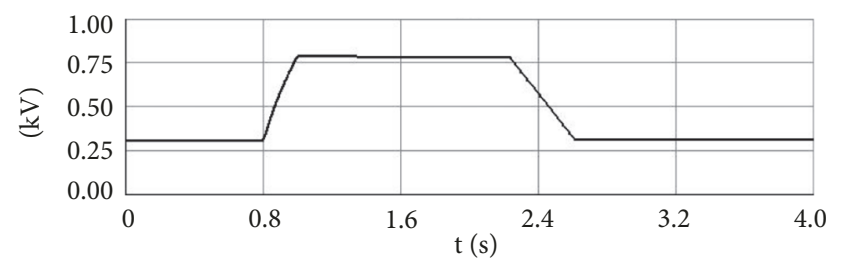

(e) Supercapacitor voltage $u_{s c}$

FIGURE 9: HiL results of GRSC with SCESU under voltage swell to $1.2 \mathrm{pu}$. 


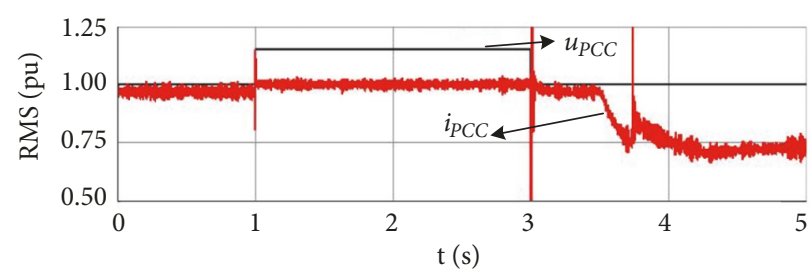

(a) Voltage and current of PCC

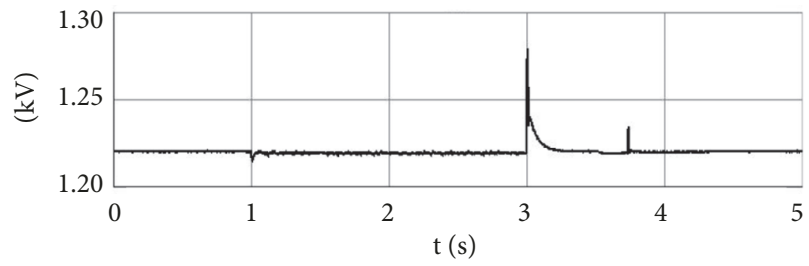

(b) DC-link voltage $u_{d c}$

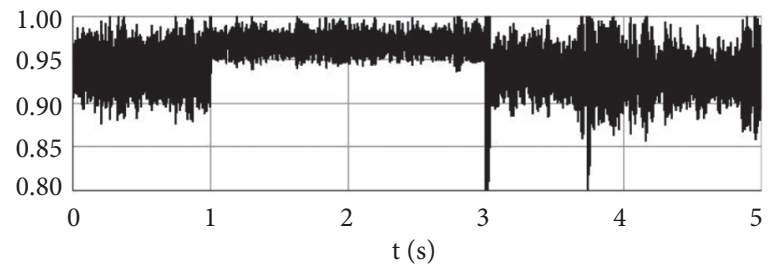

(c) Modulation of GRSC $m$

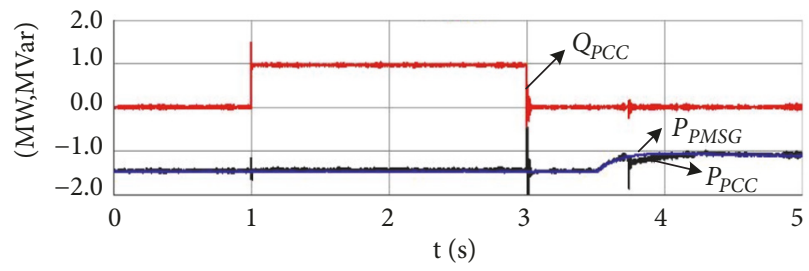

(d) Active and reactive power

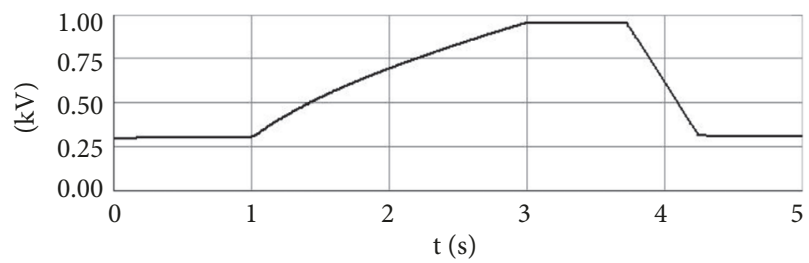

(e) Supercapacitor voltage $u_{s c}$

FIGURE 10: HiL results of GRSC with SCESU under voltage swell to 1.15pu.

\section{Data Availability}

The simulation data based on RSCAD/RTDS used to support the findings of this study are available from the corresponding author upon request.

\section{Conflicts of Interest}

The authors declare that they have no conflicts of interest.

\section{Acknowledgments}

This work was supported in part by the National Natural Science Foundation of China $(51767019,51867020)$ and in part by the Natural Science Foundation of Inner Mongolia Autonomous Region (2016MS0504, 2015MS0544).

\section{References}

[1] M. Altin, Ö. Göksu, R. Teodorescu, P. Rodriguez, B.-B. Jensen, and L. Helle, "Overview of recent grid codes for wind power integration," in Proceedings of the 12th International Conference on Optimization of Electrical and Electronic Equipment, OPTIM 2010, pp. 1152-1160, May 2010.

[2] G. Liu, F. Shi, C. Zhang, S. Wang et al., "An integrated control strategy of PMSG-based wind turbine generation system to improve its fault ride-through capability by using an energy storage device," in Proceedings of the International Conference on Renewable Power Generation, RPG 2015, October 2015. 
[3] D. Li, L. Jia, X. Xu, B. Wang, N. Wang, and X. Xie, "Cause and countermeasure analysis on wind turbines' trip-off from grid," Automation of Electric Power Systems, vol. 35, no. 22, pp. 41-44, 2011.

[4] Y. Ren, H. Hu, Y. Xue, H. Bu, and H. Niu, "Low voltage ridethrough capability improvement of PMSG based on chopper circuit and reactive priority control," High Voltage Engineering, vol. 42, no. 1, pp. 11-18, 2016 (Chinese).

[5] Z. Liu, C. Liu, and G. Li, "Coordinated power control method for improving low voltage ride through capability of wind turbines with permanent magnet synchronous generators," Automation of Electric Power Systems, vol. 39, no. 3, pp. 23-29, 2015.

[6] H. Chen, X. Hu, G. Yan, Y. Li, and X. Zhang, "A coordinated control strategy for low voltage ride-though of direct-drive permanent magnet wind power generating units," Power System Technology, vol. 37, no. 5, pp. 1464-1470, 2013.

[7] H. Li, S. Dong, Y. Wang et al., "Coordinated control of active and reactive power of PMSG-based wind turbines for low voltage ride through," Transactions of China Electrotechnical Society, vol. 28, no. 5, pp. 73-81, 2013 (Chinese).

[8] Australian Energy Market Commission, "Electricity rule change proposal: generator technical requirements," http:// www.aemc.gov.au/getattachment/1e3e9d43-a82d-4d12-ac8445e30d6eea72/Rule-change-request.aspx.

[9] State Grid Corporation of China, Technical Regulation for Wind Farm Reactive Power Configuration and Voltage Control, China Electric Power Press, 2015.

[10] Z. Zheng, H. Geng, and G. Yang, "High voltage ride-through control strategy of grid-connected inverter for renewable energy systems," Proceedings of the Chinese Society of Electrical Engineering, vol. 35, no. 6, pp. 1463-1472, 2015 (Chinese).

[11] M. Mohseni, M. A. S. Masoum, and S. M. Islam, "Low and high voltage ride-through of DFIG wind turbines using hybrid current controlled converters," Electric Power Systems Research, vol. 81, no. 7, pp. 1456-1465, 2011.

[12] K. Ren, X. Zhang, F. Wang, L. Guo, Z. Wang, and L. Wang, "Grid fault ride through of a medium-voltage three-level full power wind power converter," in Proceedings of the 8th IEEE International Power Electronics and Motion Control Conference, IPEMC-ECCE Asia 2016, pp. 1509-1514, May 2016.

[13] C. Liu, J. He, and Z. Xie, "High voltage ride-through of gridside converter for PMSG based directly driven wind turbines," in Proceedings of the 35th Chinese Control Conference, CCC 2016, pp. 8528-8532, July 2016.

[14] X. Ma, K. Dong, Y. Zhao, X. Zheng, and J. Yang, "Simulation research on fault ride through for permanent magnet synchronous generator wind power system," in Proceedings of the 9th IEEE Conference on Industrial Electronics and Applications, ICIEA 2014, pp. 1387-1391, June 2014.

[15] Y. M. Alharbi, A. M. S. Yunus, and A. Abu-Siada, "Application of STATCOM to improve the high-voltage-ride-through capability of wind turbine generator," in Proceedings of the 2011 IEEE PES Innovative Smart Grid Technologies, pp. 1-5, November 2011.

[16] A. M. S. Yunus, M. A. S. Masoum, and A. Abu-Siada, "Application of SMES to enhance the dynamic performance of DFIG during voltage sag and swell," IEEE Transactions on Applied Superconductivity, vol. 22, no. 4, 2012.

[17] C. Feltes, S. Engelhardt, J. Kretschmann, J. Fortmann, F. Koch, and I. Erlich, "High voltage ride-through of DFIG-based wind turbines," in Proceedings of the IEEE Power and Energy Society General Meeting-Conversion and Delivery of Electrical Energy in the 21st Century, pp. 1-8, IEEE, Pittsburgh, Pa, USA, July 2008.

[18] C. Wessels and W. F. Fuchs, "High voltage ride through with FACTS for DFIG based wind turbines," in Proceedings of the 13th European Conference on Power Electronics and Applications, Barcelona, Spain, 2009.

[19] G. Liu, J. Hu, G. Tian et al., "Study on high voltage ride through control strategy of PMSG-based wind turbine generation system with SCESU," in Proceedings of the 9th International Conference on Power Electronics, Machines and Drives, PEMD, Liverpool, UK, April 2018. 


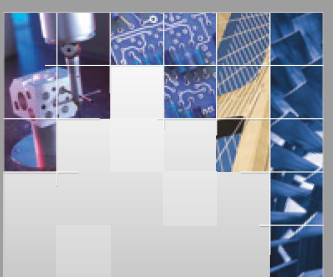

\section{Enfincering}
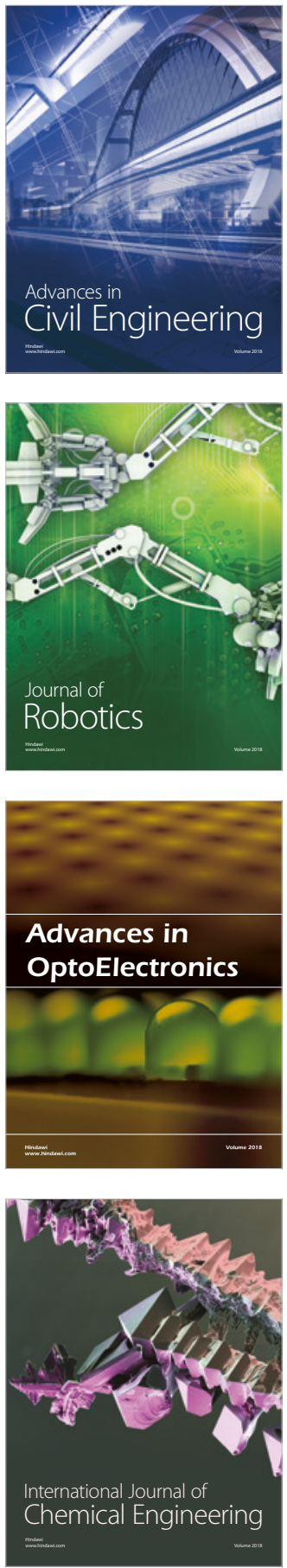

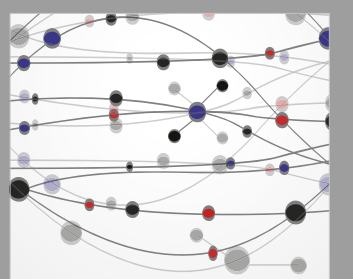

\section{Rotating \\ Machinery}

The Scientific World Journal

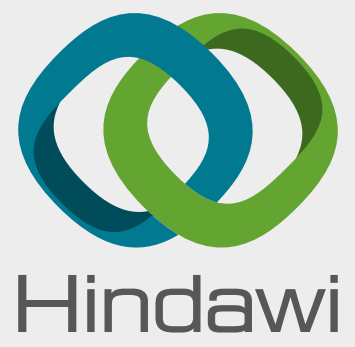

Submit your manuscripts at

www.hindawi.com
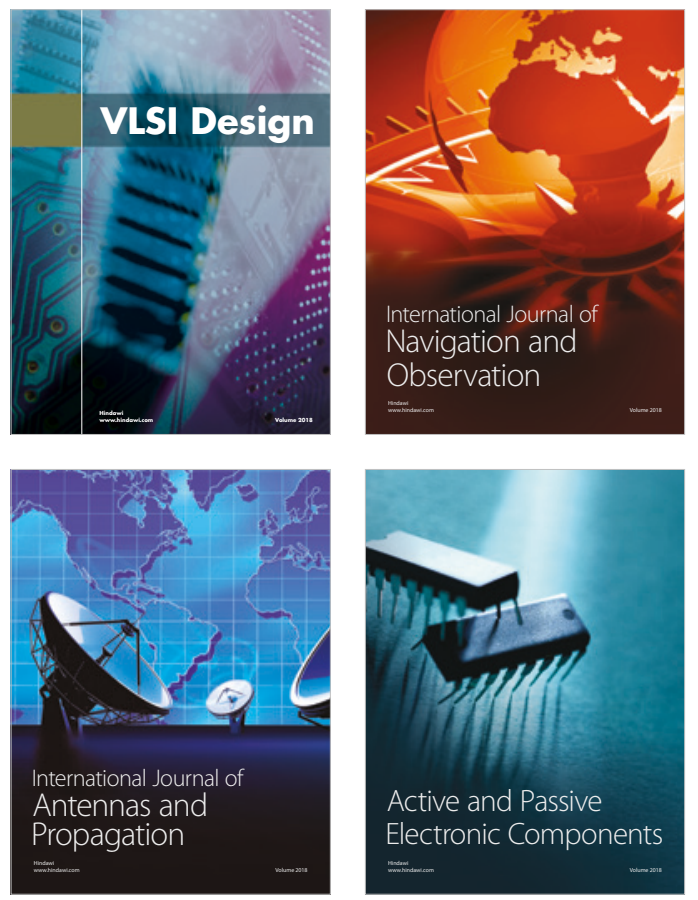
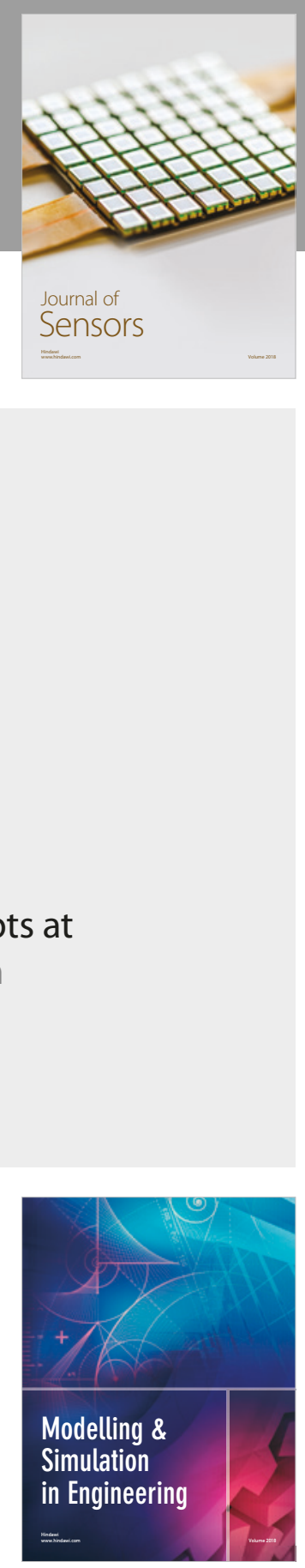

\section{Advances \\ Multimedia}
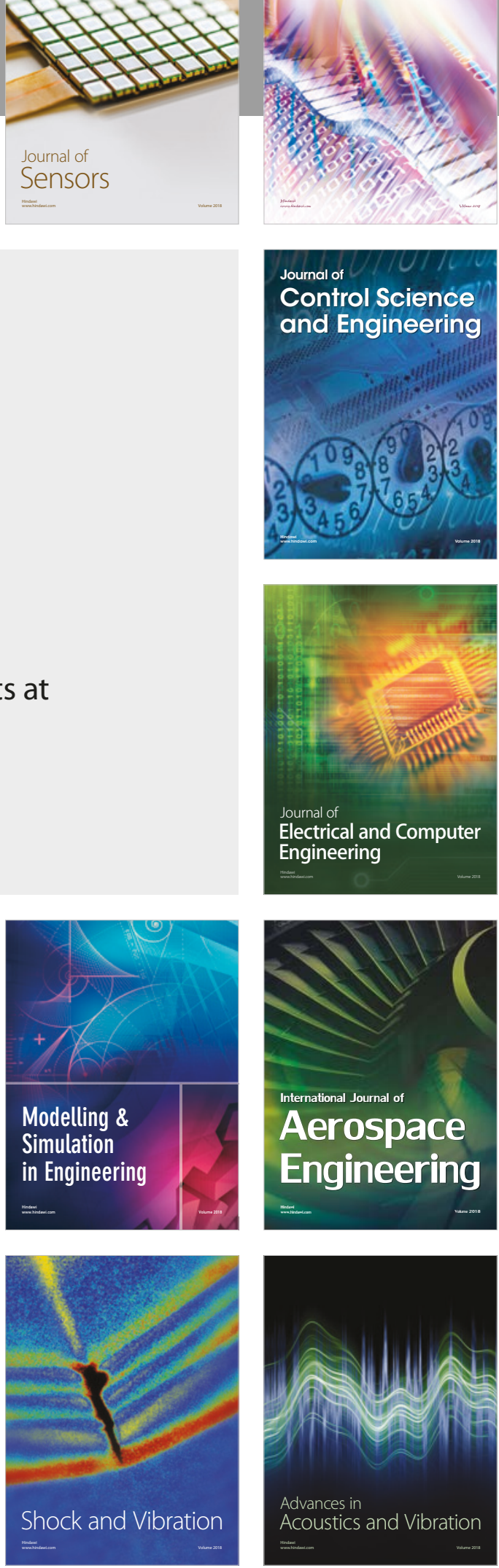